\title{
Using adalimumab serum concentration to choose a subsequent biological DMARD in rheumatoid arthritis patients failing adalimumab treatment (ADDORA-switch): study protocol for a fully blinded randomised superiority test-treatment trial
}

Maike H. M. Wientjes ${ }^{1 *}$ (D), Sadaf Atiqi ${ }^{2}$, Gerrit Jan Wolbink ${ }^{2,3}$, Michael T. Nurmohamed ${ }^{2,4}$, Maarten Boers ${ }^{4,5}$, Theo Rispens ${ }^{3}$, Annick de Vries ${ }^{3}$, Ronald F. van Vollenhoven ${ }^{2,4,5}$, Bart J. F. van den Bemt ${ }^{6,7}$ and Alfons A. den Broeder ${ }^{1,8}$

\begin{abstract}
Background: A substantial proportion of rheumatoid arthritis (RA) patients discontinues treatment with tumour necrosis factor inhibitors (TNFi) due to inefficacy or intolerance. After the failure of treatment with a TNFi, treatment can be switched to another TNFi or a bDMARD with a different mode of action (non-TNFi). Measurement of serum drug concentrations and/or anti-drug antibodies (therapeutic drug monitoring (TDM)) may help to inform the choice for the next step. However, the clinical utility of TDM to guide switching has not been investigated in a randomised test-treatment study.
\end{abstract}

Methods: ADDORA-switch is a 24-week, multi-centre, triple-blinded, superiority test-treatment randomised controlled trial. A total of 84 RA patients failing adalimumab treatment (treatment failure defined as DAS28-CRP > 2.9) will be randomised in a 1:1 ratio to a switching strategy to either TNFi or non-TNFi based on adalimumab serum trough level (intervention group) or random allocation (control group). The primary outcome is the between-group difference in mean time-weighted DAS28 over 24 weeks.

Discussion: The trial design differs in many aspects from previously published and ongoing TDM studies and is considered the first blinded test-treatment trial using TDM in RA. Several choices in the design of this trial are described, and overarching principles regarding test-treatment trials and clinical utility of TDM are discussed in further detail.

Trial registration: Dutch Trial Register NL8210. Registered on 3 December 2019 (CMO NL69841.091.19).

Keywords: Rheumatoid arthritis, Adalimumab, Anti-TNF, Therapeutic drug monitoring, Drug concentration, Switching, Test-treatment trial, Design

\footnotetext{
* Correspondence: m.wientjes@maartenskliniek.nl

'Department of Rheumatology, Sint Maartenskliniek, PO box 9011, 6500 GM Nijmegen, the Netherlands

Full list of author information is available at the end of the article
}

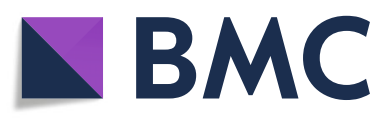

(- The Author(s). 2021 Open Access This article is licensed under a Creative Commons Attribution 4.0 International License, which permits use, sharing, adaptation, distribution and reproduction in any medium or format, as long as you give appropriate credit to the original author(s) and the source, provide a link to the Creative Commons licence, and indicate if changes were made. The images or other third party material in this article are included in the article's Creative Commons licence, unless indicated otherwise in a credit line to the material. If material is not included in the article's Creative Commons licence and your intended use is not permitted by statutory regulation or exceeds the permitted use, you will need to obtain permission directly from the copyright holder. To view a copy of this licence, visit http://creativecommons.org/licenses/by/4.0/ The Creative Commons Public Domain Dedication waiver (http://creativecommons.org/publicdomain/zero/1.0/) applies to the data made available in this article, unless otherwise stated in a credit line to the data. 


\section{Background}

Tumour necrosis factor inhibitors (TNFi) have improved treatment of rheumatoid arthritis (RA), but a proportion of patients discontinues treatment due to inefficacy or intolerance [1]. The 2019 European League Against Rheumatism (EULAR) recommendations for the management of RA advocate that any biologic agent including a subsequent TNFi can be used with on a group level equal chance for effect in case of non-response to a previous TNFi, based on a metaanalysis of three randomised controlled studies [2-6]. In addition, currently, no strong predictors for response to different types of biologic disease-modifying anti-rheumatic drugs (bDMARDs) in RA are available [7]. Therefore, after the failure of treatment with a TNFi, two approaches are viable with an equal chance of response: treatment with another TNFi (adalimumab, certolizumab, etanercept, golimumab, infliximab) or treatment with a bDMARD with a different mode of action (non-TNFi: abatacept, rituximab, sarilumab, tocilizumab).

However, it is hypothesised that therapeutic drug monitoring (measurement of drug concentrations and/or anti-drug antibodies, TDM) might help the clinician in choosing between treatment with another TNFi or treatment with a bDMARD with a different mode of action. In this study, we focus on the failure to adalimumab, a fully human monoclonal antibody TNFi that is one of the most frequently prescribed TNFi worldwide.

Failure to respond to adalimumab treatment can have multiple causes. First, some patients are not sensitive to TNF blockade and experience innate TNFi insensitivity. In these patients, switching to a non-TNFi is-at least conceptually-superior to starting a second TNFi. Secondly, approximately $30 \%$ of RA patients using adalimumab develop a substantial amount of antibodies against adalimumab (anti-drug antibodies (ADA)) that adversely affect pharmacokinetics, causing immediate (primary) or delayed (i.e. after the initial response, secondary) nonresponse [8-10]. Patients developing ADA may thus experience drug failure, but not necessarily class failure; they can still respond adequately to a second TNFi. This seems especially likely in secondary non-responders as they were primary TNFi responders; therefore, in these secondary non-responders, response rates to a second TNFi might be expected to be even higher than to a non-TNFi.

The above-mentioned hypothesis has been tested in multiple studies. Firstly, a systematic review addressing the above-mentioned hypothesis found three studies investigating TDM for prediction of response on a new bDMARD in case of inefficacy to the first bDMARD [11]. Two studies were performed in RA patients and one in a cohort of spondyloarthropathy patients [12-14]. Two studies showed that the development of ADA in patients who failed to respond to a first TNFi predicts a better clinical response to a second TNFi; one study concluded the same although this was not statistically significant. A study published more recently confirmed this, showing that RA patients with inadequate response to adalimumab, despite having sufficient adalimumab concentrations, benefit less from switching to etanercept than patients with low adalimumab concentrations [10]. These studies have some limitations, as the number of patients is limited, and test characteristics (sensitivity, specificity) were not mentioned. Additionally, as only switching from a TNFi to another TNFi is addressed, the predictive value of TDM for response to non-TNFi after failure to TNFi remains unclear. The latter is considered relevant to determine whether substantial ADA, impacting on pharmacokinetics, is able to differentially predict response to a second TNFi compared to a nonTNFi. A recent retrospective study by Ulijn et al. tried to address these issues by using larger patient numbers, assessing formal test characteristics, and including switchers to non-TNFi. This study did not show a predictive value of either ADA or randomly timed drug concentrations for obtaining a response to a second TNFi or non-TNFi [9]. This could have been due to the randomly timed sampling instead of trough level timed sampling; however, recent data suggest that results from both approaches are very comparable [15]. Of note, a recent review regarding the immunogenicity of TNFi in RA suggested that clinical effects of ADA depend on the amount of drug that is neutralised by ADA, and the amount of free drug present [16]. Even in the presence of ADA, drug concentrations can still be sufficient to reach clinical remission; therefore, measurement of serum drug concentrations is assumed to be more valid compared to ADA on its own.

In conclusion, although the use of TDM for the selection of the best subsequent DMARD in adalimumab failing RA patients seems promising, this has not yet been studied in a prospective intervention study. Therefore, we set up a randomised controlled test-treatment trial evaluating whether a switching strategy based on measurement of adalimumab trough serum concentration at the moment of failure is superior to random switching in reducing disease activity for RA patients failing adalimumab treatment with respect to disease control.

\section{Methods}

\section{Trial design}

The ADDORA-switch is a multi-centre, triple-blinded, superiority test-treatment RCT in patients with RA starting another bDMARD after adalimumab failure (Fig. 1). The study is set up in a collaboration between Reade, the Sint Maartenskliniek and Sanquin Diagnostics and funded by ZonMw and Sanquin Diagnostics. The study started on 31 July 2020 and is expected to be performed 


\begin{tabular}{|c|c|c|c|c|c|c|}
\hline & \multicolumn{6}{|c|}{ STUDY PERIOD } \\
\hline & \multirow{2}{*}{$\begin{array}{c}\text { Enrolment } \\
-2\end{array}$} & \multirow{2}{*}{$\begin{array}{c}\text { Allocation } \\
0\end{array}$} & \multicolumn{2}{|c|}{$\begin{array}{l}\text { Post- } \\
\text { allocation }\end{array}$} & \multirow{2}{*}{$\begin{array}{l}\text { Close- } \\
\text { out } \\
24\end{array}$} & \multirow{2}{*}{$\begin{array}{c}\text { Unplanned } \\
\text { visit } \\
X\end{array}$} \\
\hline TIMEPOINT (weeks) & & & 4 & 12 & & \\
\hline \multicolumn{7}{|l|}{ ENROLMENT: } \\
\hline \multirow[b]{2}{*}{ Patient information } & $\mathrm{X}$ & & & & & \\
\hline & $\mathrm{X}$ & & & & & \\
\hline Informed consent & $\mathrm{X}$ & & & & & \\
\hline Allocation of treatment & & $\mathrm{X}$ & & & & \\
\hline \multicolumn{7}{|l|}{ INTERVENTIONS: } \\
\hline \multirow{2}{*}{$\begin{array}{r}\text { Switch based on } \\
\text { adalimumab concentration } \\
\text { Switch based on usual care }\end{array}$} & & X & & & & \\
\hline & & $\mathrm{X}$ & & & & \\
\hline \multicolumn{7}{|l|}{ ASSESSMENTS: } \\
\hline Baseline characteristics & $\mathrm{X}$ & & & & & \\
\hline Disease activity & $\mathrm{X}$ & & $\mathrm{X}$ & $\mathrm{X}$ & $\mathrm{X}$ & $\bar{X}$ \\
\hline Current medication & $\mathrm{X}$ & & $\mathrm{X}$ & $\mathrm{X}$ & $\mathrm{X}$ & $\mathrm{X}$ \\
\hline Adverse events & $\mathrm{X}$ & & $\mathrm{X}$ & $\mathrm{X}$ & $\mathrm{X}$ & $\mathrm{X}$ \\
\hline Functioning & $\mathrm{X}$ & & $\mathrm{X}$ & $\mathrm{X}$ & $\mathrm{X}$ & $\mathrm{X}$ \\
\hline Routine lab tests & $\mathrm{X}$ & & $\mathrm{x}$ & $x$ & $x$ & $x$ \\
\hline $\begin{array}{l}\text { Serum for drug } \\
\text { concentration }\end{array}$ & $X$ & & $\mathrm{X}$ & $\mathrm{X}$ & $X$ & $\mathrm{X}$ \\
\hline Antidrug antibodies & $X^{*}$ & & $\mathrm{X}$ & $\mathrm{X}$ & $\mathrm{X}$ & $\mathrm{X}$ \\
\hline Genetic testing (optional) & $\mathrm{X}$ & & $\mathrm{X}$ & $X$ & $\mathrm{X}$ & $\mathrm{X}$ \\
\hline
\end{tabular}

Fig. 1 SPIRIT figure: trial visits and assessments

in at least four departments of rheumatology of hospitals in the Netherlands: the Sint Maartenskliniek, Reade, Amsterdam UMC (location VUmc) and Reumazorg Zuid West Nederland. The study has received ethical review board approval (number NL69841.091.19) and has been registered (Dutch Trial Register NL8210). A data safety and monitoring board (DSMB) will be installed which reviews data on recruitment, efficacy, safety, protocol adherence, protocol updates and results of monitoring visits. Standard Protocol Items: Recommendation for Interventional Trials (SPIRIT) checklist is shown in Additional file 1.

\section{Objectives}

The aim of this study is to evaluate whether a switching strategy based on adalimumab trough serum concentration at the moment of failure is superior to random switching in RA patients failing adalimumab treatment 
with regard to mean time-weighted disease activity score (DAS28-CRP) over 24 weeks. The secondary objectives are to compare the EULAR good response rates after 12 and 24 weeks, to compare the percentages of patients reaching low disease activity (DAS28-CRP $<2.9$ ) or remission (DAS28-CRP < 2.4) after 24 weeks, to compare percentages of EULAR non-responders to the subsequent biological and to assess the number and severity of adverse events and the use of co-medication/rescue medication.

\section{Participants}

Patients with rheumatoid arthritis (according to ACR 1987 and/or 2010 criteria and/or clinical diagnosis) who recently failed adalimumab treatment (defined as DAS28-CRP > 2.9) and are $\geq 16$ years of age are eligible to participate in this study. Patients are included if they have received adalimumab (originator or biosimilar) for at least the last 10 weeks in standard dosing $(40 \mathrm{mg}$ subcutaneously every other week, either in monotherapy or combined with methotrexate or leflunomide) and if they are due to stop adalimumab due to lack of efficacy, either alone or combined with side effects. This particular adalimumab exposition (time and dose) was chosen to ensure sufficient exposure to adalimumab to infer true failure. At inclusion, patients still have to be on adalimumab treatment to assure valid measurement of adalimumab trough concentrations and anti-drug antibodies. Treatment with co-medication, including DMARDs and prednisone, is allowed at inclusion and during the study, as this maximises the generalisability of the results to the daily clinical practice.

Patients are excluded if they had been treated with another TNFi prior to adalimumab, as these patients risk randomisation to etanercept (being their third TNFi) and evidence suggests that changes of response are lower for treatment with a third TNFi $[17,18]$. Treatment with other bDMARDs prior to adalimumab is allowed, but patients who have received all allowed nonTNFi options-abatacept, rituximab, sarilumab or tocilizumab-are excluded. Other exclusion criteria include contraindication to receive either etanercept or all allowed non-TNFi bDMARD (abatacept, rituximab, sarilumab or tocilizumab), life expectancy $<6$ months, scheduled surgery or other pre-planned reasons for treatment discontinuation during follow-up.

\section{Patient recruitment}

All eligible patients are selected and approached based on information from the electronic health record, according to the above-mentioned inclusion and exclusion criteria. The treating rheumatologist informs patients and asks them to participate in this study using a letter accompanied by the patient information sheet and the informed consent form. Patients receive this information 2 weeks prior to a planned outpatient clinic visit. Additionally, the researcher calls the patient to further explain the study, discuss the logistics of inclusion and answer the questions. If they have any additional questions, they can contact the local researcher or their treating rheumatologist. At the outpatient clinic visit, the study is discussed and informed consent is obtained. After informed consent is obtained, baseline data are collected and patients receive the allocated study medication. Patients will be recruited from four participating hospitals (the Sint Maartenskliniek, Reade, Amsterdam UMC (location VUmc) and Reumazorg Zuid West Nederland).

\section{Randomisation and blinding}

Eligible patients are randomised in a ratio of $1: 1$ to a switching strategy based on adalimumab concentration in addition to usual care (intervention group) or random switching strategy in addition to usual care (control group) (Fig. 2). Randomisation blocks are generated by an online programme and have variable block sizes ( 2 or 4 per block) to achieve the intended allocation ratio and to prevent the allocation from being predictable for the treating rheumatologist. The randomisation sequence is concealed for all trial participants and professionals (patients, physicians and assessors).

Subsequent treatment for the intervention group is based on adalimumab trough concentration. Patients with an adalimumab trough concentration below 1.0 $\mathrm{mg} / \mathrm{L}$ (either with or without measurable anti-drug antibodies) receive another TNFi, etanercept, while patients with an adalimumab concentration of $1.0 \mathrm{mg} / \mathrm{L}$ or higher receive a non-TNFi bDMARD. The choice for a particular bDMARD is left up to the treating health care provider and maybe one of abatacept, rituximab, sarilumab or tocilizumab. In the control group, patients receive instead a second randomisation to either etanercept or the same choice of non-TNFi bDMARD (abatacept, rituximab, sarilumab or tocilizumab).

A somewhat complex allocation and blinding design is used to be able to perform this comparison with patients and physicians being fully blinded. A fully blinded design is very rarely used in a test-treatment or diagnostic study but is-when feasible-the optimal design as it prevents a behavioural change in patients, physicians and assessors (expectation bias, detection bias). Also, our design results in a comparison that is as fair as possible as the proportion of TNFi and non-TNFi given to patients is harmonised by group in order to prevent that betweengroup differences originate from an imbalance in allocation and effectiveness between TNFi or non-TNFi or coDMARDs in these patients. 


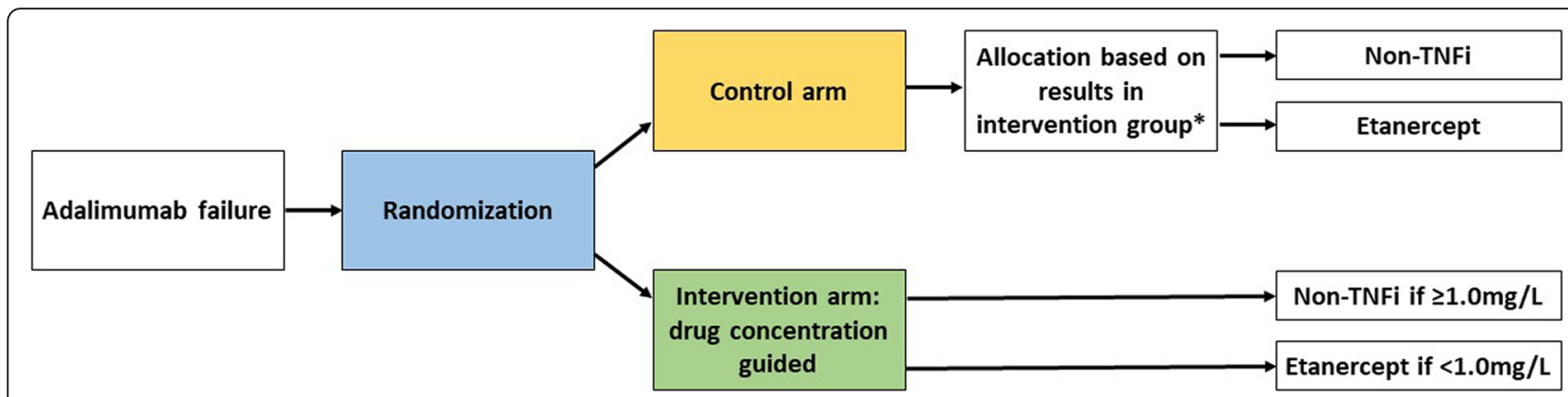

Fig. 2 Flow diagram of the ADDORA-switch study. *Allocation of subsequent treatment in the control group is directly based on allocation in the intervention group. In the case of randomisation allocating more patients to the control group than currently allocated to the intervention group, these patients will be randomised in a ratio of 1:2 to etanercept or a non-TNFi

Firstly, we blind the primary allocation to intervention (TDM) or control group and the results from the testing for adalimumab concentrations. This is done by letting an independent researcher perform the primary allocation and by sending a concrete treatment advice instead of adalimumab concentration results to study physicians. In case a patient is randomised to intervention, based on the serum adalimumab concentration (see above), the physician receives an advice to give either etanercept or a non-TNFi bDMARD chosen by the treating physician. When a patient is randomised to control, serum adalimumab concentrations are not determined immediately and treatment is based on a secondary allocation and again sent to study physicians in the form of a treatment advice. This way, the health care provider only receives a treatment advice ('etanercept' or 'non-TNFi bDMARD'), without knowing whether it is based on test result or chance.

We chose to standardise the control group as well, as preference policies regarding a second bDMARD after failure to adalimumab differ per centre. Several options were available for the secondary allocation (TNFi or non-TNFi in the control group). Ideally, this allocation would follow the same TNFi vs non-TNFi ratio as the intervention group. Therefore, a secondary randomisation with a ratio of $1: 1$ would not be optimal because previous data suggest that approximately $30 \%$ of patients have an adalimumab concentration below $1.0 \mathrm{mg} / \mathrm{L}$ [810]. A fixed 1:2 ratio TNFi vs non-TNFi would be better, but the proportion of patients with low adalimumab concentrations might be different in our population. Therefore, we chose to base the allocation of subsequent treatment in the control group directly on the allocation in the intervention group. When operationalised, this dependency means that when a patient in the intervention group is receiving etanercept, the subsequent patient randomised to the control group will also be assigned to etanercept. In case of temporary imbalance with an excess of patients allocated to the control group, these patients will be randomised in a ratio of $1: 2$ to etanercept or a non-TNFi, as this corresponds with expectations explained above.

\section{Interventions}

In both groups, patients commence treatment as explained above and visit the clinic after 1, 3 and 6 months. Of note, bDMARD treatment (etanercept, abatacept, rituximab, sarilumab or tocilizumab) may be combined with continued methotrexate or leflunomide in registered dose, according to label and clinical practice. The dosing of the subsequent bDMARD is according to the authorised dose, except for rituximab, that also may be dosed $1 \times 1000 \mathrm{mg}$ or $2 \times 500 \mathrm{mg}$ instead of $2 \times 1000$ mg i.v [19].

At every visit, disease activity will be measured by a trained physician, and patients are treated to the target of DAS28-CRP at least below 2.9. In case of an increased or persistently high disease activity between visits, patients are encouraged to contact the clinic and an additional clinic visit is scheduled. Treatment with antirheumatic co-medication during the study is allowed and left to the discretion of the treating rheumatologist; however, we aim to keep co-DMARDs stable during follow-up. Changes in co-medication during follow-up of the study are allowed in case of flare (an increase of DAS28-CRP of $>1.2$, or $>0.6$ when current DAS28-CRP $\leq 2.9$ ), adverse events, or for RA unrelated reasons. In case of active disease, bridging treatment is offered to patients, consisting of NSAIDs, methylprednisolone 120 mg i.m. (Depo-medrol ${ }^{\circ}$ ), triamcinolone i.m. $80 \mathrm{mg}$ (Kenacort ${ }^{\circ}$ ) or oral prednisone (usually $15 \mathrm{mg}$ and tapered in 2-6 weeks). In case of a persistent flare, the bDMARD can be switched to any other b/cs/tsDMARD treatment. All adverse events reported spontaneously by the subject or observed by the investigator or the physician will be recorded. To optimise protocol adherence, physicians are trained by the research team and researchers monitor adherence of the physicians and will—where needed—give feedback. 
At the first visit (baseline visit, the patient is still using adalimumab), serum samples will be collected to directly analyse trough adalimumab concentrations and antiadalimumab antibodies in intervention patients. Trough adalimumab concentrations will be measured instead of randomly timed concentrations, as literature shows more potential for trough concentrations compared to randomly timed concentrations $[9,12]$. A trough concentration is defined as the serum concentration just prior to the next injection of adalimumab, with a margin of 3 days before the injection.

\section{Testing of serum drug concentrations and anti-drug antibodies}

Trough serum adalimumab concentrations will be measured by enzyme-linked immunosorbent assay (ELISA). The detection limit of the assay is $0.001 \mathrm{mg} / \mathrm{L} \mathrm{[20].} \mathrm{A}$ cut-off concentration of $1.0 \mathrm{mg} / \mathrm{L}$ was chosen based on the combination of results from previous studies $[1,10]$. Anti-drug antibodies (ADA) will be measured using a radioimmuno assay (RIA); ADA will be expressed in arbitrary units $(\mathrm{AU} / \mathrm{mL})$. Patients were said to be positive for ADA if at one time point ADA were above the cutoff of $12 \mathrm{AU} / \mathrm{mL}$ (limit of detection [LoD]), ADA are quantifiable above $30 \mathrm{AU} / \mathrm{mL}$ (lower limit of quantification [LLOQ]). All testing will be performed by Sanquin Diagnostics, the Netherlands. The validation procedures and execution of the serum concentration and ADA assays for the adalimumab have been accredited by the RvA/CCKL (Dutch Accreditation Council/Dutch Accreditation Board for Medical Laboratories) according to the International Standardization Organization (ISO) guideline ISO15189.

\section{Outcomes}

The primary outcome of this study is the between-group difference in mean time-weighted Disease Activity Score in 28 joints (DAS28-CRP) after 24 weeks. Time-weighted means taking into consideration not only the numerical level of a variable, but also the amount of time spent on it (trapezoidal rule). The DAS28-CRP is considered a valid, reliable and broadly accepted indicator of the clinical activity of RA. Since patients are treated to target, it is possible that at the end of the study, no difference in DAS28 scores is found between the two groups, while the flaring frequency might indeed be higher in one of the groups. This is why mean time-weighted DAS28 (MTW-DAS28) is chosen above the DAS28 score at the study end. A flare is defined as an increase of DAS28CRP compared to DAS28-CRP at the former visit with $>1.2$, or $>0.6$ when current DAS28-CRP $\leq 2.9$ [21]. Any switch of DMARD, as well as bridging treatment for more than 6 weeks, is considered treatment failure. In case of treatment failure, the patients will remain in the study, but the last measure of the DAS28-CRP and other outcomes before initiation of bridging/escape medication is carried forward (last observation carried forward). Lack of response is defined as no improvement by at most 3 months after the start of the subsequent biological or the absence of low disease activity by 6 months.

Secondary outcomes include the percentage of patients with good or moderate response according to the EULAR response criteria after 12 and 24 weeks, percentage of patients with minimal disease activity (DAS28CRP < 2.9) after 24 weeks, percentage of non-responders to the subsequent biological after 24 weeks, number of flares after 24 weeks, number and severity of adverse events and use of co-medication/rescue medication.

\section{Sample size}

The power calculation for this study is based on the superiority principle, since we expect better outcomes for patients in whom the choice of subsequent biological is based on serum drug concentrations. The primary outcome, MTW-DAS28, is expected to be 2.8 in patients with low disease activity. Based on the DRESS study and STRASS study, SD of the mean time-weighted DAS28 after 24 weeks of treatment is expected to be 0.9 [22, 23]. The difference in disease activity is defined as the change in MTW-DAS28 $\geq 0.6$, as this is the measurement error of DAS28 and is considered a clinically relevant difference of clinical status in several studies [2427]. With a two-sided 5\% significance level, power of $80 \%$ and randomisation ratio $1: 1$, the sample size is 72 (36 per group). To allow for $15 \%$ dropout, the final sample size is 84 patients.

\section{Data analysis}

Data is extracted from the electronic health records and anonymously entered and stored in the data management system Castor EDC. All statistical analyses will be performed with IBM SPSS version 23 or STATAIC 13. The researcher will be blinded for allocation of intervention and control. First, data will be analysed according to intention-to-treat (ITT) analysis in order to assess efficacy potentially influenced by second-order effects. Additionally, also a per-protocol analysis will be performed as this provides the most optimistic estimate of the true efficacy of an intervention. In case of treatment failure, the last measure of the DAS28-CRP before initiation of bridging/escape medication is carried forward (last observation carried forward). The number and reasons for dropout are reported to ensure internal validity.

Descriptive statistics of baseline characteristics will be provided with mean, standard deviation, median (p25$\mathrm{p} 75)$ or $\mathrm{n}$ (\%) depending on data distribution. The size of differences in the primary outcome, mean time- 
weighted DAS28-CRP, between the two study arms will be calculated and presented. Additionally, the difference will be assessed with Student's t-test. Pre-specified adjusted analyses are performed on the primary ITT outcome, adjusting for rheumatoid factor (RF)/anticitrullinated protein antibodies (ACPA) status [28] and baseline DAS28-CRP [29]. A two-sided p-value $<0.05$ is considered statistically significant. Secondary outcomes are compared with Fischer's exact test, except for the number and severity of adverse events and the use of co-medication. Subgroup analyses will be performed to assess the differences in the effect of the intervention for patients experiencing primary ( $\leq 6$ months) or secondary (> 6 months) failure to adalimumab. No interim analyses for safety, efficacy or futility will be performed.

\section{Discussion}

The ADDORA-switch study will evaluate the additive value of measurement of adalimumab serum concentrations at the moment of failure to adalimumab in determining the subsequent biological in RA patients. The trial design differs in many aspects from previously published and ongoing TDM studies and can be considered the first test-treatment RCT using therapeutic drug monitoring in RA. Topics addressed in the design involve some interesting overarching principles we would like to discuss in further detail.

Firstly, the design of the ADDORA-switch is a rare example of a test-treatment trial in which a fully blinded design is possible. Blinding is considered very important in controlled trials, as it prevents unequal provision of care (performance bias) and biased assessment of the outcome (detection bias or expectation bias) [30]. According to a review by Ferrante di Ruffano, 76\% of testtreatment trials do not use any type of blinding; patients and physicians were only blinded in 5 and $4 \%$, respectively; and full blinding was exceptionally rare (2\%) [31]. Not blinding trial participants will have consequences on the validity of trial results as produced results risk reflecting expectations of participants, clinicians and trialists, which is known to generally cause overestimated treatment effects. However, practical and ethical difficulties involved in blinding test-treatment trial participants (patients, care providers and assessors) are part of the reason why blinding in this type of trial is particularly rare. Remarkably, the ADDORA-switch has a fully blinded design which is possible due to multiple reasons related to the test and the treatment. First, blinding for conduction of the test is not necessary as it is considered ethical to conduct serum sampling in all patients. Also, as test results are solely known by independent researchers performing the randomisation, test outcomes remain unknown for all trial participants including clinicians. Lastly, it is a substantial benefit of our trial that treatment options are comparable for both groups and used in both groups; therefore, blinding treatment is not necessary.

Another point of interest considers operationalisation of TDM in current practice, which can be logistically rather challenging for several reasons. First, it is essential to obtain the blood sample at the correct time after dosing to assess the trough drug concentration; therefore, the patient's current medication regimen has to be closely managed. Also, for interpretation, the concentration measurements and the sampling time need to be considered in relation to drug dose and dosage history. Additionally, laboratory turnaround time-the time between ordering a test and reporting of results-causes that clinicians cannot directly prescribe the new drug during consultation. Prescription of a subsequent drug based on TDM is therefore more time-consuming compared to the current practice. The last challenge is associated with the costs of additional testing. Especially when samples have to be analysed externally, analysis can be costly. Therefore, the cost-effectiveness of TDM in clinical practice has to be investigated in more detail.

Lastly, the effects of additional testing on a background of current state of art treatment strategies should be evaluated. The use of a treat-to-target strategy, which defines a treatment target and applies tight control to reach this target, is widely embedded in the treatment of RA. Following this, high disease activity is treated aggressively until patients reach and maintain remission or low disease activity, and this results in a second-order effect that might negate positive effects of TDM. Also, part of the patients will switch to another drug that would have been in line with TDM-guided switching already. We hypothesise that therapeutic drug monitoring nevertheless might contribute to channelling the right patients to the right drug, thus reducing overall disease activity and lowering the incidence of subsequent bDMARD switching.

\section{Trial status}

The trial started with the recruitment on 31 July 2020 and is currently recruiting. Recruitment is estimated to be finished in July 2022. Protocol version 2.3, 30-102020.

\footnotetext{
Abbreviations

ACPA: Anti-citrullinated protein antibodies; ACR: American College of Rheumatology; ADA: Anti-drug antibodies; ADDORA: Adalimumab dose optimization in Rheumatoid Arthritis; ADDORA-switch: Using adalimumab serum concentration to choose a subsequent biological DMARD in rheumatoid arthritis patients failing adalimumab treatment; AU: Arbitrary units; bDMARD: Biologic disease-modifying anti-rheumatic drug; CDAl: Crohn's Disease Activity Index; CMO: Commissie Mensgebonden Onderzoek; CRP: C-reactive protein; DAS28: Disease Activity Score based on 28 joints; DMARD: Disease-modifying anti-rheumatic drug; ELISA: Enzymelinked immunosorbent assay; EULAR: European League Against Rheumatism; TDM: Therapeutic drug monitoring; TNFi: Tumour necrosis factor inhibitors;
} 
ISO: International Standardization Organization; LoD: Limit of detection; LLOQ: Lower limit of quantification; MTW-DAS28: Mean time-weighted disease activity score over 28 joints; RA: Rheumatoid arthritis; RAPID-3: Routine Assessment of Patient Index Data 3; RCT: Randomised controlled trial; RIA: Radioimmuno assay; SDAl: Simple Disease Activity Index; sHAQ: Scleroderma Health Assessment Questionnaire; tsDMARD: Targeted synthetic disease-modifying anti-rheumatic drug; VAS: Visual analogue scale

\section{Supplementary Information}

The online version contains supplementary material available at https://doi. org/10.1186/s13063-021-05358-7.

Additional file 1. SPIRIT 2013 Checklist.

\section{Acknowledgements}

Not applicable.

\section{Authors' contributions}

MW, SA, GW, MB, BvdB and AdB participated in the design of the study. MW and $A d B$ were responsible for drafting this manuscript, and all other authors critically reviewed the manuscript. Furthermore, all authors approved the final version of the manuscript.

\section{Funding}

The study is funded by ZonMw (grant number 848101 006) and Sanquin Diagnostics. The study protocol was peer reviewed by external reviewers in the course of the grant application for ZonMw. There are no other financial or non-financial conflicts of interest other than specified.

The Department of Rheumatology at Reade fulfils the role as sponsor, and the Department of Rheumatology at Sint Maartenskliniek is the coordinating study centre. An independent data safety and monitoring board will be installed.

\section{Availability of data and materials}

The datasets collected during the current study are available from the corresponding author on reasonable request.

\section{Declarations}

\section{Ethics approval and consent to participate}

The study received primary ethical review board approval (number NL69841.091.19) on 24 September 2019. Ethics approval was obtained for all participating centres from the central Commissie Mensgebonden Onderzoek (CMO, committee of human research) Regio Arnhem Nijmegen, Radboud University Medical Center, PO Box 9101, 6500 HB, Nijmegen, the Netherlands. Written, informed consent to participate will be obtained from all participants prior to inclusion. The trial is registered at Dutch Trial Register, NL8210, date 3 December 2019.

\section{Consent for publication}

Not applicable.

\section{Competing interests}

Michael T. Nurmohamed: consulting fees from AbbVie, Celgene, Celltrion, Eli Lilly, Janssen and Sanofi; speaker's fees from AbbVie, Bristol-Myers Squibb, Eli Lilly, Roche and Sanofi; and research funding from AbbVie, Bristol-Myers Squibb, Celgene, Eli Lilly, Janssen, MSD, Mundipharma, Novartis, Pfizer, Roche and Sanofi. Ronald F van Vollenhoven: research support (institutional grants)_BMS, GSK, Lilly and UCB; support for educational programmes (institutional grants)_-Pfizer and Roche; consultancy, for which institutional and/ or personal honoraria were received-AbbVie, AstraZeneca, Biogen, Biotest, Celgene, Galapagos, Gilead, Janssen, Pfizer, Servier and UCB; speaker, for which institutional and/or personal honoraria were received-AbbVie, Galapagos, Janssen, Pfizer and UCB. The other authors declare that they have no competing interests.

\section{Author details}

${ }^{1}$ Department of Rheumatology, Sint Maartenskliniek, PO box 9011, 6500 GM Nijmegen, the Netherlands. ${ }^{2}$ Department of Rheumatology, Amsterdam
Rheumatology and Immunology Center, Reade, Amsterdam, the Netherlands. ${ }^{3}$ Biologics Lab, Sanquin Diagnostic Services, Sanquin, Amsterdam, the Netherlands. ${ }^{4}$ Department of Epidemiology and Data Science, Amsterdam Rheumatology and Immunology Center, UMC Amsterdam, Vrije Universiteit, Amsterdam, the Netherlands. ${ }^{5}$ Department of Rheumatology, Amsterdam Rheumatology and Immunology Center, UMC/Academic Medical Center, Amsterdam, the Netherlands. 'Department of Pharmacy, Sint Maartenskliniek, Nijmegen, the Netherlands. ${ }^{7}$ Department of Pharmacy, Radboud University Medical Center, Nijmegen, the Netherlands. ${ }^{8}$ Department of Rheumatology, Radboud University Medical Center, Nijmegen, the Netherlands.

Received: 2 April 2021 Accepted: 4 June 2021

Published online: 19 June 2021

\section{References}

1. Bartelds GM, Wijbrandts CA, Nurmohamed MT, Stapel S, Lems WF, Aarden L, et al. Clinical response to adalimumab: relationship to anti-adalimumab antibodies and serum adalimumab concentrations in rheumatoid arthritis. Ann Rheum Dis. 2007;66(7):921-6. https://doi.org/10.1136/ard.2006.065615.

2. Smolen JS, Landewé R, Bijlsma J, Burmester G, Chatzidionysiou K, Dougados $M$, et al. EULAR recommendations for the management of rheumatoid arthritis with synthetic and biological disease-modifying antirheumatic drugs: 2016 update. Ann Rheum Dis. 2017;76(6):960-77. https://doi.org/1 0.1136/annrheumdis-2016-210715.

3. Schoels M, Aletaha D, Smolen JS, Wong JB. Comparative effectiveness and safety of biological treatment options after tumour necrosis factor a inhibitor failure in rheumatoid arthritis: systematic review and indirect pairwise meta-analysis. Ann Rheum Dis. 2012;71(8):1303-8. https://doi.org/1 0.1136/annrheumdis-2011-200490.

4. Manders SH, Kievit W, Adang E, Brus HL, Moens HJ, Hartkamp A, et al. Costeffectiveness of abatacept, rituximab, and TNFi treatment after previous failure with TNFi treatment in rheumatoid arthritis: a pragmatic multi-centre randomised trial. Arthritis Res Ther. 2015;17(1):134. https://doi.org/10.1186/ s13075-015-0630-5.

5. Torrente-Segarra V, Acosta Pereira A, Morla R, Ruiz JM, Clavaguera T, Figuls $R$, et al. VARIAR study: assessment of short-term efficacy and safety of rituximab compared to an tumor necrosis factor alpha antagonists as second-line drug therapy in patients with rheumatoid arthritis refractory to a first tumor necrosis factor alpha antagonist. Reumatol Clin. 2016;12(6):31922. https://doi.org/10.1016/j.reuma.2015.11.019.

6. Smolen JS, Burmester GR, Combe B, Curtis JR, Hall S, Haraoui B, et al. Headto-head comparison of certolizumab pegol versus adalimumab in rheumatoid arthritis: 2-year efficacy and safety results from the randomised EXXELERATE study. Lancet. 2016;388(10061):2763-74. https://doi.org/10.101 6/S0140-6736(16)31651-8.

7. Cuppen BVJ, Welsing PMJ, Sprengers JJ, Bijlsma JWJ, Marijnissen ACA, van Laar JM, et al. Personalized biological treatment for rheumatoid arthritis: a systematic review with a focus on clinical applicability. Rheumatology. 2015; 55(5):826-39. https://doi.org/10.1093/rheumatology/kev421.

8. Bartelds GM, Krieckaert CLM, Nurmohamed MT, van Schouwenburg PA, Lems WF, Twisk JWR, et al. Development of antidrug antibodies against adalimumab and association with disease activity and treatment failure during long-term follow-up. JAMA. 2011;305(14):1460-8. https://doi.org/10.1 001/jama.2011.406.

9. Ulijn E, den Broeder N, Wientjes M, van Herwaarden N, Meek I, Tweehuysen $L$, et al. Therapeutic drug monitoring of adalimumab in RA: no predictive value of adalimumab serum levels and anti-adalimumab antibodies for prediction of response to the next bDMARD. Ann Rheum Dis. 2020;79(7): 867-73. https://doi.org/10.1136/annrheumdis-2020-216996.

10. I'Ami MJ, Ruwaard J, Krieckaert C, Nurmohamed MT, van Vollenhoven RF, Rispens T, et al. Serum drug concentrations to optimize switching from adalimumab to etanercept in rheumatoid arthritis. Scand J Rheumatol. 2019; 48(4):266-70. https://doi.org/10.1080/03009742.2019.1577915.

11. Van Herwaarden N, Van Den Bemt BJF, Wientjes MHM, Kramers C, Den Broeder AA. Clinical utility of therapeutic drug monitoring in biological disease modifying anti-rheumatic drug treatment of rheumatic disorders: a systematic narrative review. Expert Opin Drug Metab Toxicol. 2017;13(8): 843-57. https://doi.org/10.1080/17425255.2017.1353602.

12. Jamnitski $A$, Bartelds GM, Nurmohamed MT, van Schouwenburg PA, van Schaardenburg D, Stapel SO, et al. The presence or absence of antibodies to infliximab or adalimumab determines the outcome of switching to 
etanercept. Ann Rheum Dis. 2011;70(2):284-8. https://doi.org/10.1136/ard.2 010.135111.

13. Bartelds GM, Wijbrandts CA, Nurmohamed MT, Stapel S, Lems WF, Aarden L, et al. Anti-infliximab and anti-adalimumab antibodies in relation to response to adalimumab in infliximab switchers and anti-tumour necrosis factor naive patients: a cohort study. Ann Rheum Dis. 2010;69(5):817-21. https://doi. org/10.1136/ard.2009.112847

14. Plasencia C, Pascual-Salcedo D, Garcia-Carazo S, Lojo L, Nuno L, Villalba A, et al. The immunogenicity to the first anti-TNF therapy determines the outcome of switching to a second anti-TNF therapy in spondyloarthritis patients. Arthritis Res Ther. 2013;15(4):R79. https://doi.org/10.1186/ar4258.

15. Hooijberg F, L'ami MJ, Berkhout LC, Atiqi S, Nurmohamed M, Vries AD, et al. AB0382 Trough versus non-trough adalimumab drug level measurements. Ann Rheum Dis. 2019;78(Suppl 2):1651-2.

16. Atiqi S, Hooijberg F, Loeff FC, Rispens T, Wolbink GJ. Immunogenicity of TNF-inhibitors. Front Immunol. 2020;11:312. https://doi.org/10.3389/fimmu.2 020.00312.

17. Karlsson JA, Kristensen LE, Kapetanovic MC, Gulfe A, Saxne T, Geborek P. Treatment response to a second or third TNF-inhibitor in RA: results from the South Swedish Arthritis Treatment Group Register. Rheumatology. 2008; 47(4):507-13.

18. Blom M, Kievit W, Donders AR, den Broeder AA, Straten VH, Kuper I, et al. Effectiveness of a third tumor necrosis factor-a-blocking agent compared with rituximab after failure of 2 TNF-blocking agents in rheumatoid arthritis. J Rheumatol. 2011;38(11):2355-61. https://doi.org/10.3899/jrheum.101324.

19. Bredemeier M, Campos GG, de Oliveira FK. Updated systematic review and meta-analysis of randomized controlled trials comparing low- versus highdose rituximab for rheumatoid arthritis. Clin Rheumatol. 2015;34(10):1801-5. https://doi.org/10.1007/s10067-015-2977-z.

20. Pouw MF, Krieckaert CL, Nurmohamed MT, van der Kleij D, Aarden L, Rispens $T$, et al. Key findings towards optimising adalimumab treatment: the concentration-effect curve. Ann Rheum Dis. 2015;74(3):513-8. https://doi. org/10.1136/annrheumdis-2013-204172.

21. van der Maas A, Lie E, Christensen R, Choy E, de Man YA, van Riel P, et al. Construct and criterion validity of several proposed DAS28-based rheumatoid arthritis flare criteria: an OMERACT cohort validation study. Ann Rheum Dis. 2013;72(11):1800-5. https://doi.org/10.1136/annrheumdis-2012-2 02281.

22. Bouman CA, van Herwaarden N, van den Hoogen FH, Fransen J, van Vollenhoven RF, Bijlsma JW, et al. Long-term outcomes after disease activity-guided dose reduction of TNF inhibition in rheumatoid arthritis: 3year data of the DRESS study - a randomised controlled pragmatic noninferiority strategy trial. Ann Rheum Dis. 2017;76(10):1716-22. https://doi. org/10.1136/annrheumdis-2017-211169.

23. Fautrel B, Pham T, Alfaiate T, Gandjbakhch F, Foltz V, Morel J, et al. Stepdown strategy of spacing TNF-blocker injections for established rheumatoid arthritis in remission: results of the multicentre non-inferiority randomised open-label controlled trial (STRASS: Spacing of TNF-blocker injections in Rheumatoid ArthritiS Study). Ann Rheum Dis. 2016;75(1):59-67. https://doi. org/10.1136/annrheumdis-2014-206696.

24. van Riel PL. The development of the disease activity score (DAS) and the disease activity score using 28 joint counts (DAS28). Clin Exp Rheumatol. 2014;32(5 Suppl 85):S-65-74.

25. Porter D, van Melckebeke J, Dale J, Messow CM, McConnachie A, Walker A, et al. Tumour necrosis factor inhibition versus rituximab for patients with rheumatoid arthritis who require biological treatment (ORBIT): an openlabel, randomised controlled, non-inferiority, trial. Lancet. 2016;388(10041): 239-47. https://doi.org/10.1016/S0140-6736(16)00380-9.

26. Pope JE, Haraoui B, Thorne JC, Vieira A, Poulin-Costello M, Keystone EC. The Canadian methotrexate and etanercept outcome study: a randomised trial of discontinuing versus continuing methotrexate after 6 months of etanercept and methotrexate therapy in rheumatoid arthritis. Ann Rheum Dis. 2014;73(12):2144-51. https://doi.org/10.1136/annrheumdis-2013-203684.

27. Ndosi M, Lewis M, Hale C, Quinn H, Ryan S, Emery P, et al. The outcome and cost-effectiveness of nurse-led care in people with rheumatoid arthritis: a multicentre randomised controlled trial. Ann Rheum Dis. 2014;73(11): 1975-82. https://doi.org/10.1136/annrheumdis-2013-203403.

28. Smolen JS, Van Der Heijde DM, St Clair EW, Emery P, Bathon JM, Keystone E, et al. Predictors of joint damage in patients with early rheumatoid arthritis treated with high-dose methotrexate with or without concomitant infliximab: results from the ASPIRE trial. Arthritis Rheum. 2006;54(3):702-10. https://doi.org/10.1002/art.21678.

29. Smolen JS, Han C, van der Heijde DM, Emery P, Bathon JM, Keystone E, et al. Radiographic changes in rheumatoid arthritis patients attaining different disease activity states with methotrexate monotherapy and infliximab plus methotrexate: the impacts of remission and tumour necrosis factor blockade. Ann Rheum Dis. 2009;68(6):823-7. https://doi.org/10.1136/a rd.2008.090019.

30. Jüni $P$, Altman DG, Egger M. Systematic reviews in health care: assessing the quality of controlled clinical trials. BMJ. 2001;323(7303):42-6. https://doi. org/10.1136/bmj.323.7303.42

31. Ferrante di Ruffano L, Dinnes J, Sitch AJ, Hyde C, Deeks JJ. Test-treatment RCTs are susceptible to bias: a review of the methodological quality of randomized trials that evaluate diagnostic tests. BMC Med Res Methodol. 2017;17(1):35

\section{Publisher's Note}

Springer Nature remains neutral with regard to jurisdictional claims in published maps and institutional affiliations.

\section{Ready to submit your research? Choose BMC and benefit from:}

- fast, convenient online submission

- thorough peer review by experienced researchers in your field

- rapid publication on acceptance

- support for research data, including large and complex data types

- gold Open Access which fosters wider collaboration and increased citations

- maximum visibility for your research: over $100 \mathrm{M}$ website views per year

At BMC, research is always in progress.

Learn more biomedcentral.com/submissions 